\title{
The Effectiveness of Public Advisory Services: What are the Important Factors?
}

\author{
Suwardi Afandi Ahmad ${ }^{1} \&$ Ismail Abd Latif $^{2}$ \\ ${ }^{1}$ Technology Promotion and Development Center, Agriculture Research and Development Institute, Serdang, \\ Selangor, Malaysia \\ ${ }^{2}$ Faculty of Agriculture, Putra University of Malaysia, Serdang, Selangor, Malaysia \\ Correspondence: Suwardi Afandi Ahmad, Technology Promotion and Development Center, Agriculture \\ Research and Development Institute (MARDI), 43400 Serdang, Selangor, Malaysia. Tel: 603-8943-5960. E-mail: \\ fendi@mardi.gov.my
}

Received: July 24, 2012

Accepted: October 19, 2012

Online Published: November 8, 2012

doi:10.5539/ijbm.v7n23p19

URL: http://dx.doi.org/10.5539/ijbm.v7n23p19

\begin{abstract}
During the Ninth Malaysia Plan (9MP), the development of the SMEs has been prioritized by the government. Various initiatives were provided in order to strengthen the SMEs, especially the new start-up and micro-size firm. The initiatives provided were in the form of financial and non-financial. Among the initiatives provided are advisory services. The objective of this study is to examine what are the factors that may influence the effectiveness of advisory services offered by public institutions towards the SMEs clients. The primary data was collected from 103 small-scale food processors operating in the State of Selangor, Malaysia. The data was gathered through face to face interview using structured questionnaires. Both descriptive and exploratory factor analysis had been used to analyze the data gathered. The result of the analysis showed that there are four factors that will influence the effectiveness of public advisory services, namely prompt service, communication skills, technology and facility. In order to be effective, it is possible for the public institution to take a look on the delivery system practiced and if necessary make some improvement towards the certain elements being identified.
\end{abstract}

Keywords: SMEs profile, public advisory services, effectiveness, factor analysis

\section{Introduction}

The significant contribution of the SMEs in economic development is well documented. SMEs play a major role in providing employment for the nation, reducing an imbalance industrial structure and diversification in manufacturing activity (Moha, 1999). During the Ninth Malaysia Plan (9MP), the development of the SMEs has been prioritized by the government. It can be seen through the implementation of various government initiatives. The main focus of the government was to transform the SMEs into dynamic sector. By doing this, the SMEs were expected to be more competitive and resilient in challenging globalized economic. In line with this aspiration, the SMEs were encouraged to expand their business through the participation in high value added activity outsourced by multi-national companies (MNCs) and large corporations. The adoption of customer-driven approach and outward investment opportunities were also promoted among the SMEs.

SMEs especially the micro-size firm is vulnerable by economic fluctuation (Hakimin \& Rafi, 2010). Thus, the initiatives provided are useful in strengthening the SMEs in term of their capacity and capability. Essentially, there are various initiatives and these initiatives are available for the SMEs in all sectors. It is important to note that the initiatives provided were in the form of financial and non-financial. All this initiatives were channelled out through the relevant ministries and agencies. One of the initiatives was advisory services. Currently there have more than 15 ministries and 60 agencies involved in providing advisory services to the SMEs (SME Corp, 2010). The types of advice offered are different between agencies. As such, SMEs were encouraged to request for assistance in term of consultation from the relevant agency. By engaging with the help from the experts, it is possible for the SMEs to make some improvement on their business viability (Ndubisi, 2008), increase motivation towards the export market, enhance success in global market, keep abreast with the latest industry practices and enhance ability to meet business and financial management (SME Annual Report, 2005) In Malaysia, advisory services mostly provided by public as well as private sectors (Hakimin, Rafi \& Dahlan, 
2010). In term of the service usage, public sector would be more preferred since the SMEs clients particularly micro-size enterprises have a budget constraint to pay for the charges incurred by the private sector. For instance, Central Bank of Malaysia provides financial advisory services to SMEs and overseeing the set up of the SMEs advisory panel and counsellors by financial institution. Business and consultancy support services which cover financial advice and the preparation of business plan are provided by SME Bank. Furthermore, Credit Guarantee Corporation Malaysia Berhad (CGC) was given a mandate to provide advisory services on financial and business development, credit information services and business credit rating (SME Annual Report, 2006).

Besides that, advisory services also provided by other prominent agencies like Small and Medium Enterprise Corporation (SME Corp which formerly know as SMIDEC), Federal Agriculture Marketing Authority (FAMA), Malaysia External Trade Development Corporation (MATRADE), Malaysian Agriculture Research Development Institute (MARDI), Standards and Industrial Research Institute of Malaysia (SIRIM), Department of Veterinary Service (DVS), Department of Agriculture (DOA), Department of Fisheries (DOF), Malaysian Palm Oil Board (MPOB), Malaysian Productivity Council (MPC), People Council of Trust (MARA) and many more.

\section{Profile of the SMEs in Malaysia}

\subsection{Definition}

In Malaysia, SMEs can be identified either through annual sale turn over or number of employees (Table 1.1). The definition has been standardized by the government on 9 June 2005. The main purpose of the standardization was to formulate effective policy for the SMEs including implementation of SMEs development programme, enable better provision of technical and financial assistance, allow the government to better monitor the performance of the SMEs and evaluate the SMEs performance and contribution to the economy (Ndubisi, 2008). As for the manufacturing firm including related service and agro-based industries, the annual sale turn over or number of employees must not exceed than RM25 million or 150 employees respectively while for firm that involved in primary agriculture, services, information communication technology (ICT) and other sectors, the annual sale turn over or number of employees must not exceed than RM5 million or 50 employees respectively (National SME Development Council, 2005).

Table 1. Detail summary of SMEs definition

\begin{tabular}{|c|c|c|}
\hline Category & $\begin{array}{c}\text { Manufacturing, } \\
\text { Manufacturing Related } \\
\text { Services and Agro-based } \\
\text { industries } \\
\end{array}$ & $\begin{array}{c}\text { Services, Primary Agriculture, } \\
\text { Information and } \\
\text { Communication Technology }\end{array}$ \\
\hline Micro & $\begin{array}{l}\text { Annual sales turnover of less } \\
\text { than RM250,000 or full time } \\
\text { employees less than } 5\end{array}$ & $\begin{array}{l}\text { Annual sales turnover of less } \\
\text { than RM200,000 or full time } \\
\text { employees less than } 5\end{array}$ \\
\hline Small & $\begin{array}{l}\text { Annual sales turnover between } \\
\text { RM250,000 and less than RM10 } \\
\text { million or full time employees } \\
\text { between } 5 \text { to } 50\end{array}$ & $\begin{array}{l}\text { Annual sales turnover between } \\
\text { RM200,000 and less than RM1 } \\
\text { million or full time employees } \\
\text { between } 5 \text { to } 19\end{array}$ \\
\hline Medium & $\begin{array}{l}\text { Annual sales turnover between } \\
\text { RM10 million and RM } 25 \\
\text { million or full time employees } \\
\text { between } 51 \text { to } 150\end{array}$ & $\begin{array}{l}\text { Annual sales turnover between } \\
\text { RM1 million and RM5 million } \\
\text { or full time employees between } \\
20 \text { to } 51\end{array}$ \\
\hline
\end{tabular}

Source: National SME Development Council (2005) 


\subsection{Distribution by Sector}

Essentially SMEs formed a large portion of business establishment in agriculture, manufacturing and services sectors. According to the Census of Establishment and Enterprises 2005, SMEs accounted for 518,996 or 99.2\% of total business establishments in Malaysia. Majority of them or 411,849 were operated as micro scale, representing $79.4 \%$ of the total SMEs and $78.7 \%$ of total business establishments then followed by small scale accounted for 95,490 or $18.4 \%$ establishments and medium scale accounted for 11,657 or $2.2 \%$ of establishments. In terms of the distribution by sector, most of the SMEs prefer to involve in service sector where more than 449,004 or $86.5 \%$ SMEs were engaged in this sector with majority of them were micro scale (80.4\%) followed by small scale (17.6\%) and medium scale (2.1\%). In the manufacturing sector, about 37,866 establishments were SMEs. Half of them were operated as micro scale followed by small scale $(39.5 \%)$ and medium scale (5.2\%). Meanwhile, SMEs in the agriculture sector accounted for 32,126 and they involve mainly in food crop and market produce, horticulture and livestock with majority of them were operated as micro scale $(93.3 \%)$.

According to SME Annual Report 2006, about 34,000 SMEs in various sectors received advisory services from various government agencies. This indicates that the utilization of public advisory services is relatively low compared to the total number of SMEs in this country which accounted for 518,996 establishments (Census of Establishment and Enterprises 2005). However, for those SMEs who received the advisory services, they may have some perception towards the public institutions that provide those services.

Therefore, it is necessary to conduct a study that could be able to evaluate the impact of advice received as well as the factor affecting the effectiveness of advisory services being delivered. It is quite interesting since previous studies shows that the utilization of advisory services has increase considerably (Jianzhong and Hong, 2009; Johnson, Webber and Thomas, 2007; Stanger, 2004; and Robson and Bennett, 2000). However, this study only deals with the latter. The objective of this study is to examine what are the factors that contribute towards the effectiveness of advisory services offered by various public institutions to the SMEs clients. The data used in this study was based on the survey conducted on 103 small-scale food processors. This paper is organized as follows. The review of literature pertaining to the advisory services and factors affecting the effectiveness of advice offered will be discussed in the subsequent section. The following section will present the methodology then followed by results and discussion. Last section will deals with the conclusion of this study.

\section{Literature Review}

\subsection{Public Advisory Services}

In order to study the factors affecting the effectiveness of public advisory service, it is necessary to understand the advisory services nature. In this regard, Hjalmarsson and Johansson (2003) stated that theoretically public advisory services can be categorized into two different levels namely macro level or market intervention level and micro level or service encounter level. Under macro level, they further the discussion by comparing advisory services according to neo-classical theory and neo-Austrian perspective. Neo-classical theory characterizes advisory services as operational service and assuming it as concrete, objective, communicable and static information in all aspects in order to attain perfect market. This means that advisory services have transparent and undeniable meaning independent of the relationship between client and the service provider. Thus advice is easy to communicate and unchanged during the process of providing the service. Instead, neo-Austrian perspective purposes advisory services as strategic service and dealing with subjective, tacit and dynamic. In this regard, service and information depend largely on the relationship between the client and the service provider. Thus, advice is something that is dynamic and full of uncertainties.

Moha (1999) stated that advisory service is a government program that can be categorized into two namely management consultancy services; and product quality, quality control and design improvement. Management consultancy services are more related to the provision of supervised credit and training. The services offered including the preparation of business plan, establishment of an accounting system, cash budget and financial viability for loan application. As for quality control and design improvement, the types of services offered were standard testing, registration for quality control, research and development (R \& D), technical extension and consultation. In his study of SMEs in Malaysia, Ndubisi, 2008 categorized advisory services into two namely business and management advisory and technical advisory. Advice on marketing, accounting, finance, information technology and auditing were related to business and management advisory while R \& D on production technology, technical information on intellectual property, product innovation and certification, incubator programs and assistance to technology start-ups were put under technical advisory.

Furthermore, Schaper and Volery (2001) defined business adviser as a person who can offer specialized skills 
and knowledge in one or more aspects that is related to business operation. Business adviser also can be either an organization or individual who provide advisory services in the form of verbal or published advice that relate to financial statement, taxation, legal, business financing and operation (Stanger, 2004). According to Johnson et al. (2007), the adviser can be categorized into market-based providers and non market providers. Market-based providers normally motivated by commercial reason while non market providers motivated by non financial factors. With respect to the definition, public sectors generally fall within the non market providers.

\subsection{The use of Advisory Services}

Previous studies have plenty of discussions about advisory services usage among the SMEs. Some of the discussions focused on the utilization of advice (Lambrecht and Pirnay, 2005; Johnson et al., 2007; and Jianzhong and Hong, 2009) while some focused on both the utilization and impact of advice on the firm growth (Mole, Hart, Roper and Saal, 2009; Ramsden and Bennett, 2005; and Turok and Raco, 2000). Notwithstanding the subject matter being scrutinized, the discussion concerning the advisory services has gained much attention. In general, the use of advisory services by SMEs is determined by certain reasons and characteristics. Most cited variables that were being considered as the important determinant of firm seeking external advice were firm age and firm size. For instance, O'Farrell, Moffat and Hitchens (1993) asserted that the larger firms tend to seek advice more frequent than the smaller firm while the likelihood of older firm to use external advice is less compared to the younger counterpart. Similarly with Robson and Bennett (2000) where they also found that firm size appear to be significant explanatory variables in explaining the utilization of advisory services by firm. In this regard, they argued that the larger firm usually would experience a number of problems which require the external support to help overcome such problems. Research also indicated that there is a positive correlation between firm age and firm size with the use of advisory services (Jay and Schaper, 2003).

In other study, Jianzhong and Hong (2009) reported that firm size and sector as the important explanatory variables for advisory service usage among the Chinese SMEs. According to them, larger firm and being manufacturer were more likely to use advice from the external sources. Furthermore, they also found that the probability of firm to use advisory service will increase if the firm served the export market, having growth oriented strategy and perceived high quality as well as cost effective services. However, this study shows that firm age and advisory service usage have an inverse relationship even not significant. As mentioned, the use of advisory services is also associated with certain reason. In this regard, Adamson (2000) asserted that changes in technology that creates the knowledge gap becoming one of the reasons why the SMEs owner-manager need for an external advice. It has been suggested that the use of advisory service is a way to fill up the knowledge and skill deficiency as well as maximizing the business performance (Jay and Schaper, 2003 and Kent, 1994). Through the advisory services, the SMEs would obtain a valuable knowledge from the experts and gain intensive help in solving business problems (Hill and Neeley, 1988). Besides that, the intention to enhance product and/or service quality, improve organization and diagnosis of the enterprise were the major reasons that lead the SMEs to engage with external adviser (Lambrecht and Pirnay, 2005). Another reason is advisory services acquired would supply technical expertise to support the SMEs in running their business (Wren and Storey, 2002). According to Robson and Bennett (2000), the use of public advisory services by SMEs firms in UK is vary depends on their focus and eligibility criteria. This scenario may related to the element of trust where some of the SMEs are not confident with the government officer experience and skill and they often declare that outside agencies fail to understand their business (Mole, 2002). In some instances, SMEs complained that external advisers do not offer practical advice, do not offer value for money or they do not understand the business nature (Dyer and Ross, 2007). Thus, it can be concluded that the effectiveness of advisory services received would be the key consideration when the client made up their decision either to use public advisory service or not.

The extent to which the public advisory services is perceived as effective depends on the adviser which is the officers who are involved in providing the advices. In this regard, Chaston and Baker (1998) suggested that there have twelve elements pertaining to the adviser which may influence the effectiveness of the advice being delivered namely personal sharing, business skill, openness, competence, personal attribute, close relationship, contact regularity, consistency, availability, trustworthy, commitment and listening skill (Figure 1). In other perspective, Gibb and Manu (1990) argued that the delivery system of services practiced within the organization would influence the effectiveness of advisory services given. In that sense, they suggested that those organizations that are close to the clients with respect to people, structures, and processes employed would be able to recognize the need of clients and hence leading to greater likelihood of a positive effect. It is also necessary to highlight that the adviser job will be considered effective if the client implements what have been recommended by the adviser (Soriano, Roig, Sanchis and Torcal, 2002). 


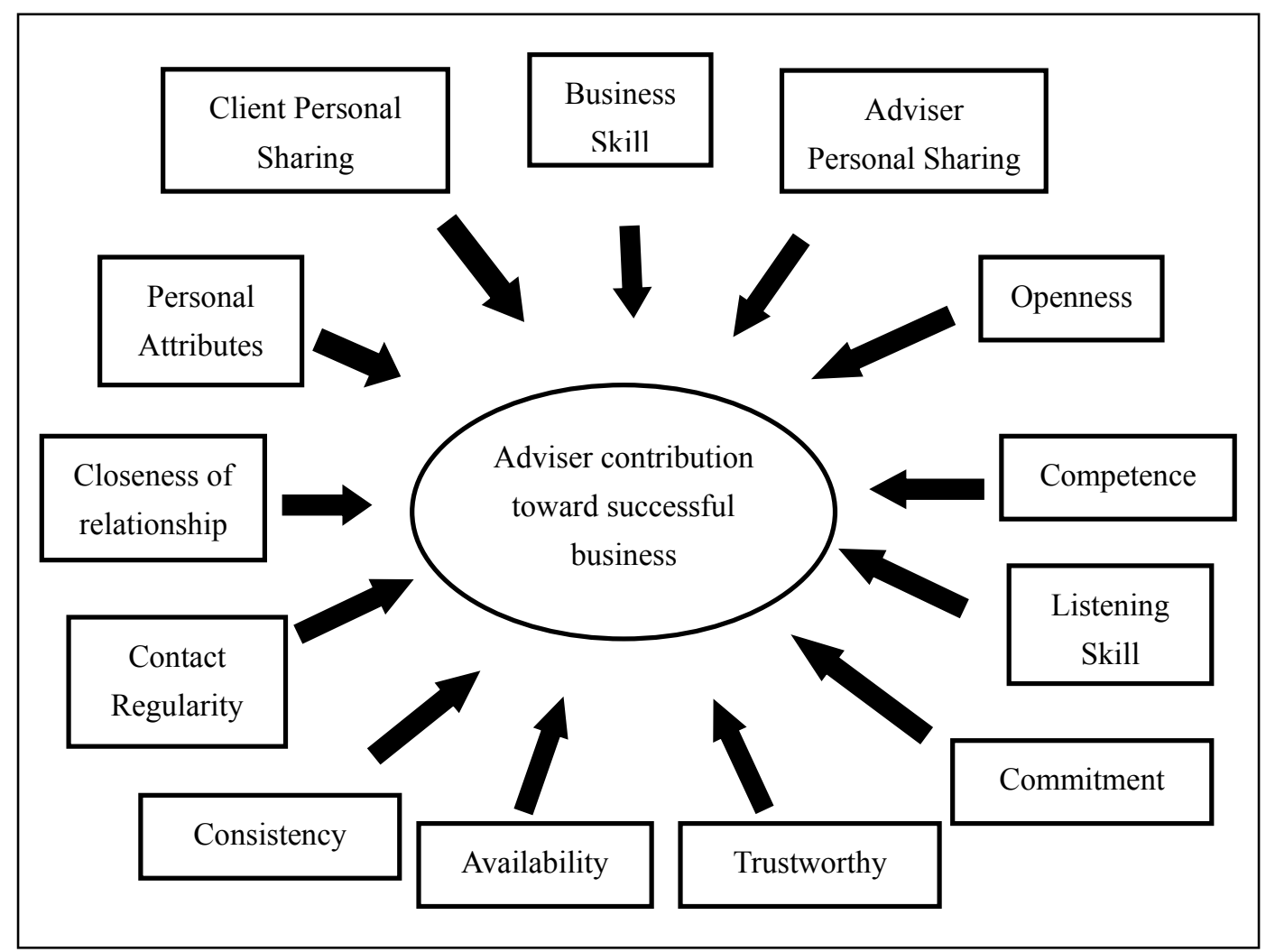

Source: Adapted from Chaston and Baker (1998)

Figure 1. Factors influencing client and advisor relationship

\section{Methodology}

\subsection{Sampling and Data Collection}

The primary data were gathered through face to face interviews using structured questionnaires. The questionnaire contained the variables pertaining to the respondent profile and a set of 23 statements that representing the delivery system of public advisory service providers. These statements were developed based on the previous studies (Chaston and Baker, 1998, and Gibb and Manu, 1990) as well as the expert help (Appendix A). The five point likert scale was used to measure the extent to which the respondent agrees or disagrees with the statements where $1=$ strongly disagree, $2=$ disagree, $3=$ not sure, $4=$ agree and $5=$ strongly agree. The location of this study was in Selangor State which becomes the centre of various public institutions that involved in providing advisory services to the SMEs clients. Our sampling frame was drawn from the list obtained from the prominent public advisory service providers namely SME Corp, MARDI, FAMA, DOA and DOF. Prior to sample selection, the list will be scrutinized in order to avoid double counting. About 201 small scale firms that involves in food processing industry were selected. These firms were initially contacted via telephone to informed them about the study and request their willingness to participate in the survey.

After being contacted, only 103 firms were available and willing to participate in this study. The face to face interview was conducted after the appointment made with the firms that agreed to be interviewed. The collection of data started from February till July 2011. Prior to data collection, pre-testing was carried out in order to validate the questionnaires content. Some changes and correction on questionnaires content was made according to the feedback received during the pre-testing. The data collected will be check manually to ensure the completeness and correctness before it being transferred into SPSS software for the analysis purposes. 


\subsection{Data Analysis}

The data were analyzed using exploratory factor analysis. The purpose of utilizing the factor analysis is to examine the underlying patterns or relationship for a large number of variables and group these variables into the smaller set of factors. Variables that are highly correlated are extracted into the same factors while uncorrelated variables are extracted into different factors (DeCoster, 1998). This procedure involves three main steps. In the first step, the correlation matrix for each variable will be identified. It was assumed that all variables are correlated with each other but the strength of the correlation is different. The second step is to extract the factor using principal component analysis. The decision to choose the number of factors which extracted from the component analysis was based on the eigenvalue. The eigenvalue is the column sum of squared loadings for a factor or the total variance accounted for by a factor (Hair, Rolph, Anderson and Ronald, 1998). Only factors with the eigenvalue greater than 1.0 will be chosen for interpretation while factor with eigenvalue less than 1.0 will be discarded. Variables with a factor loading of 0.6 and above were considered as significant because it was indicated that the factor and the variable are closely related (Muhamad Setefarzi and Tengku Mohd Ariff, 2006). Thus, factor loading with 0.6 and above will be used as the cut-off criteria in selecting the variables for each factor.

The last step is factor rotation. Initial factor matrix will be rotated using orthogonal (varimax) rotation method in order to simplify the factor structure. This procedure is desirable because the unrotated factor solution may not provide a meaningful pattern of variables loadings. According to Hair et. al. (1998), rotation can lead to better interpretation as the ambiguities that accompany the initial unrotated factor solutions were reduced. The varimax rotation method was used because this method maximizes the sum of variances of required loadings of the factors matrix and hence provides clear separation of the factors.

The Kaiser-Meyer-Olkin (KMO) test and Bartlett Test of Sphericity were used to confirm the data appropriateness before employing factor analysis. In this regard, factor analysis will be considered appropriate if the KMO value was greater than 0.5 and result of the Barlett's test of Sphericity was significant $(\mathrm{p}<0.000)$. Moreover, the degree of consistency between variables found in each factor will be measured using reliability test. The most widely used coefficient to assess the consistency of the scale is Cronbach Alpha. The scale consider reliable if it can produce the same result even the measurement was duplicated over time (Lay and Khoo, 2009). Generally, the minimum Alpha score suggested is 0.7 but it may reduce to 0.6 in exploratory research (Nunnally, 1978).

\section{Result and Discussion}

\subsection{Firms Characteristics}

The data showed in Table 2 indicates that the majority of the firm (54.3\%) were formed as sole proprietorship followed by private limited (28.2\%) and partnership (17.5\%). In term of the firm age, this study revealed that most of the firms (47.6\%) were operated for less than five years and only $17.5 \%$ were operated for sixteen years and above. Even though, the remaining $19.4 \%$ and $15.5 \%$ were operated between $6-10$ years and $11-15$ years respectively. The annual sales value of the firms ranged between RM 15, 333 and RM8.9 million, with an average of RM 531, 207. However, the annual sales value for most of the firms (40.8\%) was less than RM100, 000 . Only $15.5 \%$ of the firms were recorded annual sales value for more than RM 1,000,000. Based on the annual sale value, overall firms involved in food processing activity were classified as small-scale enterprise where $64.1 \%$ and $35.9 \%$ were categorized as micro-scale and small-scale respectively. However, based on annual sale value criteria, there is no firm categorized as medium-scale.

In term of the firm total investment, the highest was more than RM 1,000,000, which represented by $5.8 \%$. However, most of the firms (54.4\%) had investment for less than RM 100,000. About $30.1 \%$ firms had investment between RM 100,001 - RM 500,000 and the remaining 9.7\% had investment between RM 500,001 RM 1,000,000. From the total firms surveyed, about $80.6 \%$ had less than 10 workers while $5.8 \%$ employed more than 30 workers. Furthermore, $10.7 \%$ had $11-20$ workers and the least $2.9 \%$ had $21-30$ workers. Due to the size of the firm, about $89.3 \%$ still focused on domestic market while only $10.7 \%$ served both domestic and export market. This obviously showed that majority of the firms were still locally oriented in term of the market served. With respect to the product cluster, snack food considered as popular product among the firms surveyed because majority of the firms $(18.4 \%)$ chose to produce snack food, followed by bakery $(17.5 \%)$ and frozen food (13.6\%). Other food clusters such as meat based product, drink, fish based product, spices, sauces, confectionery, pasta and noodles accounted for less than $10 \%$. 
Table 2. Firm characteristics

\begin{tabular}{|c|c|c|}
\hline Characteristic & $\begin{array}{c}\text { Frequency } \\
(\mathrm{N}=103)\end{array}$ & $\begin{array}{c}\text { Percentage } \\
(\%)\end{array}$ \\
\hline Form of business & 56 & 54.3 \\
\hline Sole proprietorship & 29 & 28.2 \\
\hline Private limited & 18 & 17.5 \\
\hline \multicolumn{3}{|l|}{ Partnership } \\
\hline \multicolumn{3}{|l|}{ Firm age } \\
\hline Less than 5 & 49 & 47.6 \\
\hline $6-10$ & 20 & 19.4 \\
\hline $11-15$ & 16 & 15.5 \\
\hline 16 and above & 18 & 17.5 \\
\hline \multicolumn{3}{|l|}{ Annual sale } \\
\hline Less than RM100,000 & 42 & 40.8 \\
\hline RM100,001 - RM500,000 & 41 & 39.8 \\
\hline RM500,001 - RM1,000,000 & 4 & 3.9 \\
\hline RM1,000,001 and above & 16 & 15.5 \\
\hline \multicolumn{3}{|l|}{ Firm size } \\
\hline Micro & 66 & 64.1 \\
\hline Small & 37 & 35.9 \\
\hline \multicolumn{3}{|l|}{ Investment } \\
\hline Less than RM100,000 & 56 & 54.4 \\
\hline RM100,001 - RM500,000 & 31 & 30.1 \\
\hline RM500,001 - RM1,000,000 & 10 & 9.7 \\
\hline RM1,000,001 and above & 6 & 5.8 \\
\hline \multicolumn{3}{|l|}{ Number of workers } \\
\hline Less than 10 & 83 & 80.6 \\
\hline $11-20$ & 11 & 10.7 \\
\hline $21-30$ & 3 & 2.9 \\
\hline 31 and above & 6 & 5.8 \\
\hline \multicolumn{3}{|l|}{ Market } \\
\hline Domestic & 92 & 89.3 \\
\hline Domestic and export & 11 & 10.7 \\
\hline \multicolumn{3}{|l|}{ Product cluster } \\
\hline Snack & 19 & 18.4 \\
\hline Bakery & 18 & 17.5 \\
\hline Frozen food & 14 & 13.6 \\
\hline Meat based product & 9 & 8.7 \\
\hline Drink & 9 & 8.7 \\
\hline Fish based product & 6 & 5.8 \\
\hline Spices & 6 & 5.8 \\
\hline Sauces & 5 & 4.9 \\
\hline Confectionery & 5 & 4.9 \\
\hline Pasta and noodles & 4 & 3.9 \\
\hline Jam and spread & 1 & 1.0 \\
\hline Others & 7 & 6.8 \\
\hline
\end{tabular}

Sources: Survey data (2011) 


\subsection{Result of the Factor Analysis}

Before conducting factor analysis, we initially performed the KMO test and Barlett's test of Sphericity in order to check the data appropriateness for factor analysis. The KMO test found to be 0.891 and Barlett's test of Sphericity were significant $(p<0.000)$ at the significant level of 0.001 (Table 3 ), suggesting that the data was adequate and there was no significant correlation between the variables. Thus, indicating that the use of factor analysis was an appropriate technique for analyzing the data. The reliability analysis performed on 15 variables from the factors extracted was high with the alpha score ranges from 0.720 to 0.877 , confirming that the scale used was consistent and reliable (Table 4).

Table 3. KMO and Bartlett Test

\begin{tabular}{llr}
\hline Kaiser-Meyer-Olkin Measure of Sampling Adequacy. & .891 \\
\hline & Approx. Chi-Square & 1487.137 \\
Bartlett's Test of Sphericity & Df & 253 \\
& Sig. & .000
\end{tabular}

Sources: Survey data (2011)

Table 4. Result of the reliability test

\begin{tabular}{lcc}
\hline \multicolumn{1}{c}{ Factor } & Cronbach Alpha Scores & Number of item \\
\hline Prompt service & 0.848 & 5 \\
Communication skill & 0.877 & 6 \\
Technology & 0.732 & 2 \\
Facilities & 0.720 & 2 \\
\hline
\end{tabular}

Sources: Survey data (2011)

Result of the factor analysis after performing the rotation procedure is presented in Table 5. The table contained the factor loading which represents the correlation between the variables and the factors. The exploratory factor analysis performed in this study had identified four factors with eigenvalues greater than unity and the total variance accounted was $64.274 \%$. The factors were named according to the variables loaded in the each factor.

The first factor is prompt service. This factor had a significant loading on five variables with total variance explained of 45.973 percent and the eigenvalues was 10.574. The second factor was communication skill which consists of six variables. The total variance and eigenvalues obtained for this factor were 7.863 percent and 1.809 respectively. Technology was the third factor which had a total variance of 5.866 percent and eigenvalues of 1.439. This factor had a significant loading on two variables. The last factor was facilities which also had significant loading on two variables. This factor had a total variance of 4.572 percent and eigenvalues of 1.052 .

The findings of this study were different from what has been recommended by Gibb and Manu (1990). Such differences occurred in term of the dimension extracted where previous finding recognized that the effectiveness of institutions that involved in providing advisory services was influenced by peoples, structures and processes while our study revealed that the effectiveness of public institutions would be influenced by prompt service, communication skill, technology and facility. This occurred probably because of the type of the advisory services being offered, socio-economic and demographic background, culture and environment.

However, this study gained a valuable knowledge and will be able to enrich the existing literatures. Through this study, we know that the most critical factor that will contribute towards the effectiveness of public advisory services was prompt services. The findings suggested that the public advisory service providers need to ensure that their officers always give quick response upon client requests, immediate feedback on application result, 
convenient to contact and always available for their consultation, perform frequent site visit and keep their promise when dealing with client. At the same time, the officers should also carry the role of the adviser by acquiring relevant knowledge, confidence, proper clothing and being a good listener. Even though it is not critical, but the elements of technology and facility should not be neglected as these elements also play an important role in influencing the effectiveness of public advisory service providers.

Table 5. Summary of factor analysis results

Items
Factor loading

1
$2 \quad 3$

4

\begin{tabular}{ccc}
\hline Prompt service & \\
i) & Quick response upon client requests & 0.839 \\
ii) & Quick feedback on application result & 0.779 \\
iii) & Officers are easy to contact and available & 0.731 \\
& when need their consult & \\
iv) & Performing the site visit & 0.617 \\
v) & Keep promise when dealing with client & 0.614 \\
\% of variance explained & 45.973
\end{tabular}

Communication skill

i) Comfortable and easy to communicate with the officers

ii) Knowledgeable and expert in the area referred

iii) Well dressed, good looking and appearance

iv) Always give good opinion and positive advice

v) Confident to conduct the consultations

vi) Interested to listen the problem raised by client

Technology

i) Attractive and user friendly website

ii) Adopting latest information technology

Facility

i) Attractive office and physical facilities

ii) Comfortable parking space, waiting and discussion room

$\%$ of variance explained

Total variance explained

64.274

Sources: Survey data (2011) 


\section{Conclusion}

The purpose of this study is to identify what are the important factors that could influence the effectiveness of public advisory services. This study involved 103 small-scale food processors in the State of Selangor. The firms had received advisory services from various public institutions and their perception toward the effectiveness of public advisory services was captured through the structured questionnaires during the face to face interview. Based on the exploratory factor analysis conducted, this study revealed that there are four factors that have greater influence toward the effectiveness of public advisory services. Among these factors, prompt service was a very critical followed by communication skills, technology and facility.

The result of this study suggests that the public institutions should revise and strengthen the delivery system. They need to put greater emphasize on the element of prompt service, human capital, technology and facility. All unnecessary processes and procedures should be eliminated. As the processes and procedures eliminated, the length of the time used to accomplish certain task also can be reduced and hence lead them to act quickly. Moreover, the institutions must be ensure that their officers especially the front liners should have sense of urgency mind set in doing their job, give priority and focus for the potential SMEs, try to understand the SMEs by keeping good relationship with them as well as performing regular visit to the SMEs premises. Those younger officers should prepare themselves with greater knowledge and communication skill. This would help them to answer any questions raised by clients without waiting for consultation from the senior officers.

Due to the important of human capital, the officers should equip themselves with greater expertise on a specific area. They also need to be confident during the consultation process. In this regard, they must appear as resourceful and skilful person. In the meantime, all institutions should recognize the officer level of competency, creativity and ability with the aims to empowering them on certain decision making. Of course the institutions should provide intensive training as well as relevant courses to their manpower that involves in extension works especially the new one. It is possible to establish industrial extension centre to train and recruit the government officers to be expert in providing extension and advisory services in food processing industry. At the same time, the element of technology should not be neglected. All infrastructures pertaining to the information communication technology (ICT) must be upgraded accordingly. Special focus should be given on the state or district level office with poor ICT application. The use of up-to-date ICT application could speed up the working process. Beside that, it could help to inculcate paperless culture among the public institutions.

Moreover, the institutions also need to put all information pertaining to their services into their website. The website should be view as important media to disseminate all information to the target groups. Hence, the website should be update frequently with their latest events or activities. On the other hand, the public institutions must make sure that their offices are attractive, attached with directional signs, inquiry counter as well as proper landscaping. Physical facilities such as parking space, waiting and discussion room should be comfortable. As to facilitate access among those SMEs located in sub-urban and less developed regions, the development of branch network or one stop centre also can be considered (Moha Asri, 1999). 


\section{References}

Adamson, I. (2000). Management consultant meets a potential client for the first time: the pre-entry phase of consultancy in SMEs and the issues of qualitative research methodology. Qualitative Market Research: An International Journal, 3(1), 17-26. http://dx.doi.org/10.1108/135s22750010310415

Census of Establishment and Enterprises. (2005). Department of Statistics. Putrajaya, Malaysia.

Chaston, I., \& Baker, S. (1998). Relationship influencers: determination of affect in the provision of advisory services to SME sector firms. Journal of European Industrial Training, 22(6), 249-256. http://dx.doi.org/10.1108/03090599810224710

De Coster, J. (1998). Overview of factor analysis. Retrieved on 15 November 2011 from http://www.stat-help.com/notes.html

Dyer, L. M., \& Ross, C. A. (2007). Advising the small business client. International Small Business Journal, 25(2), 130-151. http://dx.doi.org/10.1177/0266242607074517

Gibb, A., \& Manu, G. (1990). The design of extension and support services for small-scale enterprise development. International Small Business Journal, 8(3), 10-26. http://dx.doi.org/10.1177/026624269000800301

Hair, J. F., Rolph, E., Anderson, \& Ronald, L. T. (1998). Multivariate Data Analysis (5 ${ }^{\text {th }}$ Edition). Upper Saddle River: Prentice Hall.

Hill, C., \& Neeley, S. (1988). Differences in the consumer decision process for professional vs generic services. Journal of Services Management, 2(1), 17-23. http://dx.doi.org/10.1108/eb024712

Hjalmarsson, D., \& Johansson, A. W. (2003). Public advisory services: Theory and practice. Entrepreneurship and Regional Development, 15(2), 83-98. http://dx.doi.org/10.1080/0898562021000011205

Jay, L., \& Schaper, M. (2003). Which advisers do micro firm use? Some Australian evidence. Journal of Small Business and Enterprise Development, 10(2), 136-143. http://dx.doi.org/10.1108/14626000310473166

Jiang, Z. X., \& Hong, F. (2009). An empirical study of usage of external business services by Chinese SMEs. Journal of Enterprise Information Management, 22(4), 423-440. http://dx.doi.org/10.1108/17410390910975031

Johnson, S., Webber, D. J. B., \& Thomas, W. (2007). Which SMEs use external business advice? A multivariate sub-regional study. Environment and Planning A, 25(5), 439-357.

Kent, P. (1994). Management advisory services and the financial performance of clients. International Small Business Journal, 12(4), 45-58. http://dx.doi.org/10.1177/0266242694124003

Lambrecht, J., \& Pirnay, F. (2005). An evaluation of public support measures for private external colsultancies to SMEs in the Wallon Region of Belgium. Entrepreneurship and Regional Development, 17(2), 89-108. http://dx.doi.org/10.1080/0898562042000338598

Lay, Y. F., \& Khoo, C. H. (2009). Introduction to computer data analysis with SPSS 16.0 for windows. Venton.

Moha, \& Asri, A. (1999). The accessibility of the government sponsored support programmes for small and $\begin{array}{llll}\text { medium-sized enterprises in } & \text { Penang. }\end{array}$ http://dx.doi.org/10.1016/S0264-2751(99)00003-7

Mohd Nor Hakimin, Y., \& Mohd Rafi, Y. (2010). The government business support services in Malaysia: The evolution and challenges in the new economic model. International Journal of Business Management, 5(9), $60-71$.

Mohd Nor Hakimin, Y., Mohd Rafi, Y., \& Mohamed Dahlan, I. (2010). Business advisory: A study on selected miro-sized SMEs in Kelantan, Malaysia. International Journal of Marketing Studies, 2(2), 245-257.

Mole, K. (2002). Business advisers impact on SMEs: An agency theory approach. International Small Business Journal, 20(2), 139-162. http://dx.doi.org/10.1177/0266242602202002

Mole, K. F., Hart, M., Roper, S., \& Saal, S. D. (2009). Assessing the effectiveness of business support services in England: Evidence from a theory-based evaluation. International Small Business Journal, 27(5), 557-582. http://dx.doi.org/10.1177/0266242609338755

Muhamad Seterfarzi, M. N., \& Tengku Mohd Ariff, T. A. (2006). Problems and constraints of the local herbs and medicinal plants (HMP) processing industry. Economic and Technology Management Review, 1(1), 
$61-70$.

National SME Development Council. (2005). Central Bank of Malaysia, Kuala Lumpur, Malaysia.

Ndubisi, N. O. (2008). Small and Medium Enterprises in the Pacific Rim. Arah Publication.

Ninth Malaysia Plan. (2006). Ninth Malaysia Plan 2006-2010. Putrajaya, Malaysia: Economic Planning Unit, Prime Minister's Department Malaysia. Retrieved from http://www.epu.gov.my/

Nunnally, J. L. (1978). Psychometric theory (2 ${ }^{\text {nd }}$ Edition). McGraw-Hill. New York.

O’Farrell, P. N., Moffat, L. A. R., \& Hitchens, D. M. W. N. (1993). Manufacturing demand for business services in a core and peripheral region: does flexible production imply vertical disintegration of business services? Regional Studies, 27, 385-400. http://dx.doi.org/10.1080/00343409312331347645

Ramsden, M., \& Bennett, R. J. (2005). The benefit of external support to SMEs: Hard versus soft outcomes and satisfactions level. Journal of Small Business and Enterprise Development, 12(2), 227-243. http://dx.doi.org/10.1108/14626000510594629

Robson, P. J. A., \& Bennett, R. J. (2000a). The use and impact of business advice by SMEs in Britain: an empirical assessment using logit and ordered logit models. Applied Economics, 32(13), 1675-1688. http://dx.doi.org/10.1080/000368400421020

Schaper, M., \& Volery, T. (2001). Entrepreneurship and Small Business. In Schaper, M., \& Jay, L. (2003). Which advisers do micro firms use? Some Australian evidence. Journal of Small Business and Enterprise Development, 10(2), 136-143. http://dx.doi.org/10.1108/14626000310473166

Small and Medium Enterprise Corporation. (2010). SME Development Framework. Retrieved on 20 October 2010 from http://www.smeinfo.com.my/index.php/en/sme-definition/developing-malaysian-smes/government-strategi es/sme-framework

SME Annual Report. (2005). National SME Development Council, Central Bank of Malaysia. Kuala umpur, Malaysia.

SME Annual Report. (2006). National SME Development Council, Central Bank of Malaysia, Kuala umpur, Malaysia.

Soriano, D. R., Roig, S., Sanchis, J. R., \& Torcal, R. (2002). The role of consultants in SMEs: The use of services by Spanish industry. International Small Business Journal, 20(1), 95-103. http://dx.doi.org/10.1177/0266242602201007

Stanger, A. M. J. (2004). Gender comparative use of small business training and assistance: a literature review. Education and Training, 46(8/9), 464-473. http://dx.doi.org/10.1108/00400910410569588

Turok, I., \& Raco, M. (2000). Developing expertise in small and medium sized enterprise: an evaluation of consultancy support. Environment and Planning C: government and Policy, 18, 409-428. http://dx.doi.org/10.1068/c9868

Wren, C., \& Storey, D. J. (2002). Evaluating the effect of soft business support upon small firm performance. Oxford Economic Papers, 54, 334-365. http://dx.doi.org/10.1093/oep/54.2.334 